\title{
A robótica no ensino de matemática
}

\section{Robotics in mathematics teaching}

Recebido: 26/06/2019 | Revisado: 15/02/2020 | Aceito: 15/02/2020 | Publicado: 04/01/2021

Odair José Kunzler

ORCID: https://orcid.org/0000-0002-3623279X

Instituto Federal Farroupilha - IFFar, Brasil E-mail: odair.kunzler@iffarroupilha.edu.br

Marcele Homrich Ravasio

ORCID: http://orcid.org/0000-0003-01621426

Instituto Federal Farroupilha - IFFar, Brasil E-mail:

marcele.ravasio@iffarroupilha.edu.br

Sandra Bazana Nonenmacher

ORCID: http://orcid.org/0000-0003-27355154

Instituto Federal Farroupilha - IFFar, Brasil E-mail:

sandra.nonenmacher@iffarroupilha.edu.br

Taniamara Vizzotto Chaves

ORCID: https://orcid.org/0000-0003-4872-

1141

Instituto Federal Farroupilha - IFFar, Brasil

E-mail: tvchaves@yahoo.com.br

Como citar: KUNZLER, O. J.; RAVASIO, M. H.; NONENMACHER, S. B.; CHAVES, T. V. A robótica no ensino de matemática. Revista Brasileira da Educação Profissional e Tecnológica, [S.I.], v. 1, n. 20, p. e8761, jan. 2021. ISSN 2447-1801. Disponível em:

$<$ http://www2.ifrn.edu.br/ojs/index.php/RBE $\mathrm{PT} /$ article/view/8761>

This work is licensed under a Creative Commons Attribution 4.0 Unported License.

\begin{abstract}
Resumo
O emprego de recursos tecnológicos em sala de aula pressupõe o caminho inverso de suas concepções. Oriundos de avanços científicos que se propagam dos bancos escolares e universitários para fora dos muros dessas instituições, encontrando espaço cada vez maior em um mundo que se constitui de tecnologias, agora são estas que se voltam às instituições de ensino, fomentando práticas educativas que visam facilitar os processos que permeiam a educação. O presente artigo apresenta a análise de uma Oficina de Robótica em uma escola pública, atividade de extensão da disciplina de Matemática, que objetiva integrar conhecimentos teóricos multidisciplinares à prática da criação de robôs e, por consequência, despertar nos discentes 0 interesse pelas ciências envolvidas nesse processo. Nesse sentido, a proposta deste trabalho é avaliar, através de uma abordagem qualitativa de um estudo de caso, a repercussão que a oficina de robótica tem assumido no processo de ensino e aprendizagem dos alunos participantes. Como resultado, é possível identificar que os participantes da oficina têm apresentado avanços na apropriação de conteúdos relacionados à Matemática, assumindo postura diferenciada em relação àqueles que não participam da mesma atividade.
\end{abstract}

Palavras-chave: Educação; Práticas educativas; Tecnologias.

\section{Abstract}

The use of technological resources in the classroom presupposes the inverse path of their conceptions. As a result of scientific advances that spread from school and university banks outside the walls of these institutions, finding an increasing space in a world of technologies, these are now turning to educational institutions, fostering educational practices aimed at facilitating the processes that permeate education. This paper presents an analysis of a Robotics Workshop in a public school, an extension activity of the Mathematics discipline, which aims to integrate multidisciplinary theoretical knowledge to the practice of robot creation and, consequently, to awaken in students the interest in the sciences involved in this. process. In this sense, the proposal of this work is to evaluate, through a qualitative approach of a case study, the repercussion that the robotics workshop has assumed in the teaching and learning process of the participating students. As a result, it is possible to identify that the participants of the workshop have presented advances in the appropriation of contents related to Mathematics, assuming a differentiated posture in relation to those who do not participate in the same activity.

Keywords: Education; Educational practices; Technologies. 


\section{INTRODUÇÃO}

O presente estudo discorre acerca de uma proposta de ensino chamada "Oficina de Robótica", que é desenvolvida em uma escola estadual, de ensino médio, na cidade de Chapecó, situada no oeste catarinense. A prática educacional em questão não mantém uma relação formal com a disciplina de Matemática, em que pese ter sido motivada há alguns anos e, até hoje, ser ofertada aos discentes pelo professor desta disciplina; trata-se, antes de tudo, de uma atividade de extensão que envolve alunos voluntários de diferentes séries do ensino médio daquela instituição, integrando conhecimentos de vários campos do saber. De acordo com o professor que coordena o projeto, a oficina tem por objetivo aplicar conhecimentos de física, de informática e de modelagem matemática à robótica, através de protótipos desenvolvidos em equipe.

Nesse sentido, o que se propõe fazer aqui é conjugar as atividades desenvolvidas na prática educacional analisada - Oficina de Robótica - aos conceitos abordados na disciplina de Teorias e Práticas de Ensino e Aprendizagem, ofertada no Programa de Mestrado Profissional em Educação Profissional e Tecnológica do Instituto Federal Farroupilha, no Campus de Jaguari/RS, sobretudo no tocante à corrente cognitivista, a qual encontra lastro na transição para um paradigma da educação que Marques (2000) chama de paradigma da Pós-Modernidade.

Inicialmente será descrita a prática educativa que foi objeto de análise: sua concretização, os primeiros momentos, o processo de seleção dos participantes, o ambiente em que se desenvolve, o papel do professor em sala de aula, as dinâmicas que permeiam essa prática, os processos cognitivos que subjazem o desenvolvimento dos protótipos e outros apontamentos que se fizerem relevantes. Nesse momento, é importante relacionar os movimentos que ocorrem durante as práticas da oficina de robótica com as concepções de Moreira (2015) sobre cognitivismo, buscando inserir essa proposta de ensino (ou projeto de ensino, ou ainda, prática de ensino) nesta teoria de aprendizagem. Silva (2010) e Monereo (2010) darão subsídios para justificar os processos de interação que ocorrem na prática educativa analisada, além de referenciar a importância do uso de tecnologias no processo de ensino e aprendizagem, sobretudo relacionando a formação de saberes a partir dos processos construtivos. Cumpre ressaltar, porém, que as impressões acerca da Oficina de Robótica,, assim como as informações acerca de sua origem e seu desenvolvimento, antecedem à análise realizada a partir da observação in loco, uma vez que este autor já mantinha contato prévio com o professor idealizador da prática educativa em foco e acompanhava as movimentações da oficina através de publicações em rede social.

Na parte final do artigo será abordada a relação que a Oficina de Robótica tem com a apropriação de conhecimentos que serão, posteriormente, levados para 0 ambiente formal de ensino: a sala de aula. Sobre tal, Pozo (1999) destaca a capacidade da mente humana de "modificar-se a si mesma" (p. 83) através da reflexão consciente, característica que pode ser extraída do diário de campo inventariado a partir da observação do espaço da Oficina de Robótica. Dessa forma, para além de transcrever uma prática educativa que encontra escopo nas tecnologias disponíveis em ambiente escolar, o que este artigo se propõe a fazer é, também, situar essa proposta dentro de uma teoria de aprendizagem que melhor a represente, destacando, por fim, de que forma ocorre sua contribuição para a atividade fim de 
qualquer prática relacionada à educação: facilitar os processos de ensino e de aprendizagem.

\section{OFICINA DE ROBÓTICA: CONSTRUINDO SABERES A PARTIR DA REFLEXÃO E DA PRÁXIS}

O emprego de tecnologias em sala de aula tem assumido papel relevante no desenvolvimento de diversas práticas educativas, alimentado principalmente pelo acesso facilitado aos recursos necessários, seja através da aquisição própria pelas instituições de ensino, seja oriundo de políticas públicas de fomento ao uso dessas ferramentas, vislumbrando a inserção da escola em um novo cenário, sobre o qual Monereo (2010) destaca:

Fruto da nova tecnologia foram os primeiros computadores digitais, no fim da década de 1940, que encontrariam na corrente comportamentalista e suas máquinas de ensino analógico um terreno fértil para o desenvolvimento da educação assistida por computador que, apesar das críticas recebidas, continua com boa saúde e presente em muitas aplicações edumáticas atuais (MONEREO, 2010, p. 20).

A Oficina de Robótica se constitui distante do paradigma essencialista e se aproxima do paradigma educacional da Pós- Modernidade. Para Marques (2000) no paradigma educacional essencialista ensinar significava transmissão de verdades fiéis e imutáveis pelo professor e a aprendizagem medida pela quantidade delas que são reporduzidas nas provas. As aulas transcorriam com base na teoria comportamentalista e seus processos de estímulo-resposta, repetição, controle do comportamento, castigos, recompensas e avaliações. Na Oficina de Robótica, podemos perceber, traços de outro paradigma educacional, definido por Marques (2000), como da Pós-Modernidade baseado na hermeneutíca da argumentação, em que o ensino se fundamenta no diálogo dos sujeitos únicos e diversos e a aprendizagem "no alargamento do horizonte cultural, relacional e expressivo, na dinâmica das experiências vividas e na totalidade da aprendizagem da humanidade pelos homens" (p.122). Em diversos momentos da oficina as atividades se voltam para cada sujeito envolvido, consciente de sua simetria e igualdade de possibilidades.

As primeiras ocorrências de emprego de robótica educativa são datadas da década de 1950; entretanto, de acordo com Schons et al (2008), foi somente a partir da década de 80, alicerçando-se na teoria construtivista de Jean Piaget, que a programação e a construção de robôs como práticas educativas ganhou destaque em universidades e, posteriormente, alcançou escolas de nível fundamental e médio.

A oficina surgiu em meados do ano 2014, em uma escola de ensino médio, localizada na região central do município de Chapecó, em Santa Catarina. Um dos professores de Matemática daquela instituição, ao vasculhar os materiais guardados em um laboratório de informática, encontrou protótipos de robôs, peças e outros equipamentos destinados à aplicação de robótica em ambiente escolar. Tais equipamentos faziam parte de uma política pública estadual de incentivo ao uso de tecnologias nas escolas, criada anos antes, porém, sem profissionais com formação para trabalhar com tais elementos, a instituição guardou-os. Motivado pela 
potencialidade desses equipamentos, o professor acordou com a Direção da instituição sobre resgatá-los e empregá-los em um projeto de ensino. Com a aquiescência da Direção, um professor de uma universidade local que possuía conhecimento em robótica foi convidado para ministrar as primeiras oficinas na escola. Formou-se, então, uma turma de cerca de 20 alunos interessados em participar da atividade, oriundos dos três anos do ensino médio. Após estes encontros iniciais, as práticas passaram a ocorrer regularmente às quintas-feiras, a partir das 19 horas, no Laboratório de Informática daquela instituição. Desde o segundo ano da implementação da Oficina de Robótica, apenas o professor de Matemática é responsável por coordenar o projeto e mantê-lo em atividade.

A respeito do emprego desse tipo de ferramenta, Gonçalves e Aroca (2014) destacam que

a Robótica Educacional consiste em uma importante ferramenta interdisciplinar e motivacional que pode se constituir em importante auxílio ao processo de ensino-aprendizagem, por possibilitar a inserção tecnológica dos alunos na cultura digital e transformar informação em conhecimento ( p. 7).

Anualmente ocorre o ingresso de novos alunos na oficina, preenchendo as vagas deixadas pelos concluintes do ensino médio. Além dessas, o professor que coordena o projeto destaca que sempre há outras vagas que são abertas à medida que alguns participantes abandonam a oficina no decorrer do ano letivo. Essas desistências, observa o professor, acometem principalmente os discentes que têm dificuldades em desenvolver atividades coletivas, em que as decisões precisam ser tomadas pela articulação de todo o grupo de participantes. Nesse sentido, tem-se que a Oficina de Robótica é uma prática educativa que prevê a integração de todos os participantes, priorizando a construção coletiva de saberes e reproduzindo no ambiente escolar características que os alunos encontrarão na vida real.

\begin{abstract}
A educação sintonizada com o nosso tempo pode engendrar a repercussão complexa da comunicação e do conhecimento para assimilar o presente e o futuro interativos. Antes, a escola contava com a predisposição do sujeito forjada também pela mídia da massa e simulava, em sala de aula, a vida real dos alunos do futuro: o mundo das fábricas e da distribuição em massa. Hoje quando as novas tecnologias interativas libertam o sujeito da massificação imposta pelos meios clássicos, a escola se depara com a autonomia do sujeito que faz por si mesmo e o convida à comunicação e ao conhecimento no confronto coletivo, para simular, em sala de aula, a vida real que os alunos podem ter (SILVA, 2010, p. 200).
\end{abstract}

Da mesma forma como os alunos têm liberdade para se desligarem da oficina, a eles também é facultado o ingresso nesta. Não há um processo de seleção definido além da livre manifestação da vontade em participar, basta o discente ter tempo para dedicar nas noites das quintas-feiras às atividades de planeamento e desenvolvimento dos projetos e, quando a equipe adere a competições de robótica, possuir disponibilidade para realizar as atividades que são inerentes as provas.

Na noite em que foi realizada a visita à Oficina de Robótica, no final do mês de março de 2018, apenas seis alunos e o professor participavam das atividades que 
duraram pouco mais de duas horas. Sem a presença de nenhum robô, as discussões giravam em torno do próximo campeonato que seria disputado, no qual seria vencedor o protótipo que vencesse uma prova de força. Por essa razão, a pauta do grupo consistia em debater conceitos da física sobre força, superfície, massa e aderência de materiais.

Além de evidenciar que a motivação para as práticas da oficina é a participação em campeonatos (sejam locais, regionais ou em território nacional), observou-se que o professor atua principalmente como um articulador do grupo, sem delegar tarefas e sem transferir conhecimentos aos alunos; de outra forma, a construção do conhecimento se dá a partir da necessidade do grupo em encontrar soluções para as demandas produzidas pela competição em foco. Os saberes prévios são trazidos para o momento atual e as possibilidades de resultados são avaliadas ainda no nível da abstração. Moreira (2015, p. 15) destaca que "essa postura deixa de ver o aluno como um receptor de conhecimentos, não importando como os armazena e organiza em sua mente. Ele passa a ser considerado agente de uma construção que é sua própria estrutura cognitiva".

Com relação aos processos mentais envolvidos e à forma como se dá a construção do conhecimento, observa-se que as discussões suscitadas pelo grupo em análise, problematizando situações futuras sempre com fulcro em saberes que cada membro traz consigo, explicita que "a filosofia cognitivista trata, então, principalmente, dos processos mentais; se ocupa da atribuição de significados, da compreensão, transformação, armazenamento e uso da informação envolvida na cognição" (MOREIRA, 2015, p. 15).

Barros et al (2017) destacam que o emprego de robôs em sala de aula "constitui-se numa ferramenta investigativa e lúdica onde se emprega a criatividade do discente na criação de soluções de hardware e software visando a resolução de um desafio" (2017, p. 11-12). Neste processo de busca por solução a um problema estabelecido, tendo a robótica como elemento fundante para a sua resolução, muitos conceitos e procedimentos, das diferentes áreas do conhecimento, necessitam ser mobilizados. Cabe destacar que o pensamento lógico matemático e o computacional são indispensáveis para a resolução de diversos problemas relacionados às tecnologias, porém não bastam, como afirma Libardoni (2018).

\begin{abstract}
Até o momento, a maioria das utilizações das tecnologias em robótica na educação têm como foco dar suporte ao ensino de conteúdos que são próximos ao campo da robótica enquanto ciência, como a programação de robôs, construção e mecatrônica. Além disso, outra abordagem comum é utilizar a robótica no aprendizado de conceitos de áreas correlatas como a física, ciências e matemática. Se quisermos alcançar os alunos independente de suas aptidões, é preciso pensar em projetos mais amplos. Uma perspectiva mais abrangente quanto aos saberes e objetivos de seu uso tem potencial para engajar as crianças e os jovens com os mais diversos interesses. Na busca por essa perspectiva, precisamos desenvolver novas e inovadoras formas de tornar mais atrativo o desenvolvimento de projetos de robótica. (LIBARDONI, 2018, p.70)
\end{abstract}

Na prática observada e aqui relatada, o docente é professor de Matemática, - que facilita a apreensão de conceitos matemáticos, pois caso eles sejam necessários o professor faz a intervenção na direção de auxiliar na compreensão 
destes por parte dos estudantes que participam da Oficina. Nesse sentido, há um ganho significativo para o Ensino de Matemática na escola, pois por mais que poucos estudantes participem do projeto, no quantitativo de alunos do Ensino Médio na escola, a forma como os conteúdos matemáticos se fazem presentes e são por estes estudantes apropriados, reverte em uma modificação na imagem da disciplina de Matemática escolar como apenas a reprodução e resolução de equações e cálculos sem significado real.

A prática docente interativa observada na Oficina de Robótica rompe com posturas tradicionais no processo de ensino e aprendizagem. Para Silva (2010, p. 188), esse comportamento promove mudanças na comunicação em sala de aula e permite "enfrentar o descompasso evidente entre o modelo de comunicação emergente e o modelo hegemônico que subjaz à instituição escolar", qual seja, a transmissão-recepção do conhecimento. O mesmo autor assevera:

\begin{abstract}
Refiro-me à possibilidade de o professor promover participação-intervenção, bidirecionalidade-hibridação e permutabilidade-potencialidade, aproveitando a confluência oportuna das esferas social, tecnológica e mercadológica, num mesmo espírito de tempo entendido como lógica da comunicação. Romper com a prevalência da transmissão e converter-se em formulador de problemas, provocador de interrogações, coordenador de equipes de trabalho, sistematizador de experiências e memória viva de uma educação que, em lugar de aferrar-se no passado, valoriza e possibilita o diálogo entre culturas e gerações (SILVA, 2010, p. 188).
\end{abstract}

Nota-se que a presença do professor é de extrema relevância à manutenção da Oficina de Robótica; entretanto, é notória, também, que a mudança de postura que esse assume diante da equipe permite ao grupo imergir num processo de desconstrução ou desacomodação dos saberes e, a partir de então, buscar reorganizar os novos saberes para dar conta da proposta em que está inserido, movimento que gera a possibilidade de aprender através da construção dos saberes.

Finalmente, antes de partir para a análise de como as atividades desenvolvidas na Oficina de Robótica contribuem para a construção de conhecimentos em sala de aula, importa referir o viés multidisciplinar que a subjaz. Como já mencionado anteriormente, conceitos de Física dominaram as discussões durante a observação da prática educativa. Além dessa disciplina, no entanto, conhecimentos de Modelagem Matemática, de Informática e de Automação são constantemente trabalhados nas oficinas, seja no desenvolvimento dos protótipos, seja no processo manual de construção destes. Para além da prática em si, existe os momentos de integração entre as variadas equipes que participam das competições. Conforme o professor, antecedem esses encontros, contatos entre as equipes, trocas de informações e várias outras situações que são facilitadas a partir do uso de tecnologias de informação e de comunicação disponíveis nas diversas instituições participantes. 


\section{ASSIMILAÇÃO DE CONHECIMENTOS ATRAVÉS DA ROBÓTICA}

Ao analisar de que forma as práticas desenvolvidas na Oficina de Robótica repercutem em sala de aula, faz-se necessário lançar luz sobre uma constatação que o professor que coordena o projeto deixou desvelado. Ao tratar sobre os discentes que deixam de participar da oficina, sobretudo aqueles que o fazem por não conseguir trabalhar coletivamente, o professor entende que esse comportamento é uma característica inata, sendo o sujeito propenso a ter mais sucesso nas atividades que requerem introspecção e individualidade, mas não sendo este o perfil que logra êxito na proposta analisada, a qual se constituiu na interação dos participantes.

De outra forma, o docente observa que, entre os alunos que permanecem no projeto, os mais reservados e menos expressivos na equipe, ainda que contribuam nas discussões do grupo, tendem a não modificar seu comportamento inicial, especialmente em sala de aula. Dito de outra forma, apesar da modificação do ambiente em que está inserido, o aluno não modifica seu comportamento, o que irá contribuir para a conclusão de que a prática educativa analisada age com maior intensidade no campo da cognição.

Pozo (1999) afirma que dentre as maneiras de entender as diversas possibilidades teóricas e trazê-las para uma base comum é "assumir que no enfoque cognitivo existem diferentes níveis de análise, que podem não só ser diferenciados, mas integrados" (p. 82). O autor sugere quatro planos distintos em que poderia ser analisada a mente humana, de acordo com sua complexidade, e sempre emergindo para o nível seguinte a partir dos anteriores. O conhecimento produzido na Oficina de Robótica, como se verá a seguir, perpassa esses quatro planos distintos.

O primeiro nível de complexidade que Pozo (1999) menciona é a conexão entre as unidades de informação. De acordo com o autor,

\footnotetext{
A aprendizagem implicaria adquirir novas pautas de ativação conjunta ou conexão dessas unidades neuroniais (neurônios que compõem o cérebro humano), formando redes. O conhecimento estaria distribuído entre essas múltiplas unidades ativadas simultaneamente ou de modo paralelo, de forma que aprender implicaria modificar a conexão entre essas unidades (p. 83).
}

Percebe-se aqui que o autor considera que o conhecimento é um processo interno, que pressupõe gerar um desequilíbrio, uma mudança entre as unidades neuronais, criando uma possibilidade de aprendizagem. Na prática educativa analisada, esse desequilíbrio é trazido pelos desafios das competições de robótica, que lançam aos membros do grupo tarefas que, para serem cumpridas, devem ser antecedidas de reflexão sobre aquilo que já se sabe e sobre novas possibilidades de construção. Os saberes prévios são resgatados e reorganizados de acordo com a necessidade futura dos participantes. Nesse momento, tem-se consagrado o segundo plano de complexidade, denominado "A aquisição e mudança de representações" e que trata das representações do mundo através da conexão entre as unidades citadas. 
Essas representações se conservariam e organizariam num "armazém" de memória mais ou menos permanente, regido por seus próprios processos, que junto com os próprios mecanismos de aquisição e mudança das representações e outros processos auxiliares, como a motivação, a atenção ou a recuperação do aprendido, constituiriam os processos de aprendizagem. Este nível de análise corresponde à concepção clássica do processamento de informação, que concebe o sistema cognitivo humano como um mecanismo de representação do conhecimento, que consiste numa série de memórias conectadas através de certos processos (POZO, 1999, p. 83).

O terceiro nível de complexidade, que o mesmo autor denomina "A consciência reflexiva como processo de aprendizagem" (POZO, 1999, p. 83), aborda a capacidade da mente humana de agir por processos de reflexão consciente, modificando representações. Na prática, é esse processo que permite aos sujeitos investigados na Oficina de Robótica dar conta de corrigir problemas antes mesmo de eles acontecerem, aplicando o conhecimento que já têm às novas situações que lhes são apresentadas. Pozo (1999, p.83-84) destaca que "podemos assumir que a consciência não é um estado mental, mas também um processo efetivo de aprendizagem, daí que, seja como alunos ou professores, devemos fomentar essa consciência que nos permite modificar o que sabemos".

Por fim, o quarto nível de complexidade é reservado pelo autor para mostrar como o conhecimento se articula a partir de uma prática social, deslocando o armazenamento das representações não mais na mente do aprendiz, mas distribuída entre as pessoas (POZO, 1999).

Nesta perspectiva acredita-se que a construção do conhecimento na prática educativa analisada se dá pela articulação de informações dos sujeitos; informações que são reorganizadas conscientemente à medida que se faz necessário atingir um novo objetivo.

Em vez de um processo automático de reforço ou consolidação dos conhecimentos que têm êxito, como no caso da aprendizagem associativa, a construção de conhecimentos requer que se tome consciência das diferenças entre essa nova informação e as estruturas que tentam assimilá-la ou compreendê-la (POZO, 1999, p. 130).

A respeito da proposta de construção coletiva do conhecimento na Oficina de Robótica, é importante destacar que "a cooperação entre aprendizes promoverá melhores resultados quando se trata de incentivar uma aprendizagem construtiva ou reflexiva entre os alunos" (POZO, 1999, p. 258). Nesse sentido, a interação entre os membros é fundamental para que a equipe obtenha o êxito que se espera.

Finalmente, ao observar o desempenho dos estudantes que participam da Oficina de Robótica na sala de aula, o professor destaca a capacidade de reflexão dos mesmos. Segundo o docente, esta é a principal característica apresentada pelos estudantes arrolados, os quais tendem a ser mais cautelosos ao buscar soluções para problemas ou encontrar caminhos para a resolução de desafios, incorrendo numa quantidade menor de erros que os demais. Para Pozo (1999), esse comportamento pode ser compreendido como decorrente de "uma prática reflexiva, em que o aluno 
deve aprender o que está fazendo" (p. 91). Esse tipo de prática, segundo o mesmo autor, implicará em uma aprendizagem mais significativa.

\section{CONSIDERAÇÕES FINAIS}

Refletir acerca da prática educativa permite voltar-se para o mundo que está constituído a nossa volta, assim como para a forma como nos inserimos neste. A velocidade com que as tecnologias surgiram e se desenvolveram na pós-modernidade é maior que a capacidade que as escolas tiveram no sentido de se apropriarem delas para fomentar os processos de ensino e de aprendizagem.

A Oficina de Robótica traz em seu bojo essas particularidades, por lançar mão de recursos tecnológicos para promover a construção de conhecimento.

No âmbito da Educação Profissional e Tecnológica, atividades como essa oficina tendem a alcançar grande êxito. Primeiramente, não há como consagrar ensino integrado sem lançar mão dos recursos tecnológicos que permeiam a sociedade e com os quais os discentes terão de atuar no mundo do trabalho. Para além disso, é notório o reflexo positivo que os processos cognitivos envolvidos na robótica produzem nos sujeitos envolvidos. Trata-se, pois, de uma atividade que agrega diversas áreas do saber e que produz resultados em todas elas, com reflexo, inclusive, em outras.

Levar práticas como a Oficina de Robótica para outras instituições é creditar ao estudante a ideia de sujeito epistêmico que o cientista Jean Piaget tratava, um sujeito capaz de produzir conhecimento, de construir relações, de observar, de organizar e reorganizar, de explicar, de abstrair e de antecipar.

\section{REFERÊNCIAS}

BARROS, R. P., et al. CardBot: Tecnologias assistivas para imersão de deficientes visuais na robótica educacional. In: Workshop de Robótica Educacional, 5, 2014. São Carlos. Anais... São Carlos: Editora Sociedade Brasileira de Computação SBC, 2014. p. 11-16.

GONÇALVES, L. M. G.; AROCA, R. V. História do WRE. In: Workshop de Robótica Educacional, 5, 2014. São Carlos. Anais... São Carlos: Editora Sociedade Brasileira de Computação - SBC, 2014. p. 7-9.

LIBARDONI, G. C. Oficina de Robótica no Ensino Médio como metodologia de construção de conhecimentos de Ciências Exatas. Programa de Pós-Graduação em Educação em Ciências: Química da Vida e Saúde. Porto Alegre: UFRGS, 2018 ( Tese de Doutorado)

MARQUES, M. O. A Educação no limiar do terceiro milênio, exigente de outro paradigma. Revista Contexto e Educação. n. 59. p 113-128. Disponível em: https://www.revistas.unijui.edu.br/index.php/contextoeducacao/article/view/1235. Acesso em 27/02/2018. 
MONEREO, C. C. C, et al. Psicologia da Educação Virtual: Aprender e Ensinar com as Tecnologias da Informação e da Comunicação. Porto Alegre: Armed, 2010.

MOREIRA, M. A. Teorias de Aprendizagem. 2 ed. São Paulo: E.P.U., 2015.

POZO, J. I. Aprendizes e Mestres: A Nova Cultura da Aprendizagem. Porto Alegre: Alianza Editorial, 1999.

SCHONS, C.; PRIMAZ, É.; WIRTH, G. A. P. Introdução a Robótica na Instituição Escolar para alunos de Ensino Fundamental da disciplina de Língua Espanhola através das novas tecnologias de aprendizagem. Florianópolis: PUCRS, 2008.

SILVA, M. Sala de aula interativa. 5. ed. São Paulo: Edições Loyola, 2010. 